\title{
Predicting Time-Lag Stock Return Using Tactical Asset Allocation Trading Strategies Across Global Stock Indices
}

\author{
Fahim Afzal ${ }^{1}$, Pan Haiying ${ }^{1}$, Farman Afzal $^{2} \&$ Faisal Ghafoor Bhatti ${ }^{3}$ \\ ${ }^{1}$ Business School of Hohai University, Nanjing, China \\ ${ }^{2}$ School of Management and Economics, University of Electronic Science and Technology of China, Chengdu, \\ China \\ ${ }^{3}$ Edith Cowan University, Western Australia \\ Correspondence: Fahim Afzal, Business School of Hohai University, Nanjing 210098, Jiangsu, China. Tel: \\ 152-6185-8637.
}

Received: September 11, 2019

Accepted: October 12, 2019

Online Published: October 21, 2019

doi:10.5430/ijfr.v11n1p115

URL: https://doi.org/10.5430/ijfr.v11n1p115

\begin{abstract}
This paper investigates the effectiveness of different tactical asset allocation trading strategies on global stock market indices in order to better forecast the returns. It has been revealed that timing model strategies are appeared to be the best performing one than the passive buy and hold strategy. Results show that the simulated moving average is the best strategy in order to generate buy and sell signals to minimize the investor's risk and maximize the return of the portfolio. It has been recommended that investors who are looking to minimize the risk of their portfolio and decrease the drawdown can use the proposed timing model strategy to achieve a balanced portfolio in the future.
\end{abstract}

Keywords: stock return, market timing model, buy and hold strategy, trading strategies

\section{Introduction}

Since the existence of stock markets, financial investors are trying to forecast stock prices by identifying patterns with technical trading analysis to enhance their profit returns (Turner, 2007). The essence of all technical trading strategies is the belief that security prices are predictable with the use of technical indicators (Edwards, Magee, \& Bassetti, 2018; Murphy, 1999). Technical trading strategies are commonly used topic in academic financial literature. Moving averages is one of the oldest technical trading strategies, where a simple moving average is considered and used as an indicator to buy or sell any stock. Most of the early work done shows that practical trading strategies usually are not generating profits. According to Dale and Workman (1980) and James (1968) moving average trading procedures are not actually generating profits and actually unable to outperform a passive buy and hold strategy.

However, some recent works demonstrate few shreds of evidence about predicting power of market especially when investors use technical trading strategies. Brock et al. (1992) in their well-known article published, observed different trading strategies and concluded that some technical trading strategies are significantly generating profits. In their study, the two most popular strategies are studied-trading range breakout rules and moving average. Brock et al. (1992) also studied and observed the variation on the Dow Jones for a period of 90-years and found substantial trading profits (excluding transaction costs). The backside of the study is that Brock et al. (1992) only used U.S. stock data in their research. Bessembinder and Chan (1995) reproduce the study of Brock et al. (1992) but do incorporate operation costs and non-synchronous trading. Their study affirmed the positive results of Brock et al. (1992) and find that indeed simple trading strategies have substantial forecasting power but when transaction costs are involved excess profits are wiped-out.

Stock market volatility is the term for uncertainty or chance regarding the changes in a security's value. Larger volatility signifies that securities' values are spread out more than a greater range of beliefs. This means that the price of your stability can transform dramatically more than a few days interval within either route. Lesser volatility signifies that any security's value will not change dramatically, nevertheless changes within value with a continuous tempo more than some time. It is an established fact that high volatility diminishes compound returns (Kilgallen, 2012). For enhancing the risk-adjusted returns multiple kinds of research have been conducted. Many of these claiming the possibilities of market risk-adjusted returns' outperformance by moving average trading strategies, it means the stock 
could perform well by using moving average trading strategies instead of buy and hold strategy.

This study aims to investigate whether the risk-adjusted returns on equity among several asset classes can be improved by suggesting the right time to enter and exit from the market using tactical asset allocation trading strategies. Subsequently, the timing model strategy could also generate buy and sell signals in order to indicate the right time for the investment. This study has compared different timing model strategies with traditional buy and hold strategy to find out the performance of key global stock indices. This study helps the investors to select better forecasting strategies across different stock indices to enter and exit the market at the best of the time in order to maximize returns.

\section{Literature}

Technical analysis according to Wong et al. (2003) plays an important role in signaling the timing of buying or selling of stocks. Using the technical analysis for projection as done by Fama (2006) seemed to be controversial at the beginning. But, Wong et al. (2003) proved that technical analysis is a significant tool for forecasting exact time regarding buying or selling stocks. A test indicator of drawdown is incorporated to find results that check whether buying and selling of stocks give the differences in return or not. Technical analysis is a technique in which information about the market is extracted into objective visualization by the use of mathematics with a major focus on the behavior of investor keeping in mind the supply and demand to explain the current and predict the future path of the financial market (Ciana, 2011).

Timing model initially was elaborated by (Faber, 2007). In the model, a simple quantitative approach to tactical asset allocation was discussed by explaining the time at which you buy or sell a stock. The application of this model was related to trade indices like S\&P 500, MSCI EAFE, GSCI, and United States government 10-year treasury bonds. The price based system used was based on mechanical logic. The simple moving average was a long term indicator to calculate the extent of risk. Faber (2007) observed that risk-adjusted returns are improved when the model was applied to different asset classes. Minimization of risk followed by an increase in returns for stocks upon which timing model was implemented.

The Kilgallen's (2012) approach was further supported by many researchers who worked on the timing model for buy and hold strategy. Major asset classes were taken, constructing a diversified portfolio that carried the equal weights. The asset classes included the U.S. bonds, stocks, international stocks, real estate and commodities. He computed a 10 month moving average of closing prices for each asset. Portfolio at the end of each month depicted a decrease in asset value below the level of moving average. At this point, an asset can be sold and the cash can be held. Thus, after examining moving average approach, the assets can be repurchased in the case if there is an upward trend.

Technical analysis indicators like compound annual growth rate, standard deviation, maximum drawdowns, and Sharpe ratio were used in the timing model. Droke (2001) explained in order to measure the overall performance of stocks, certain indicators are proved to be dependable on each other. Moving averages can be used as an indicator to get positive results. The mean value of all security prices is achieved using moving averages for the specific time period. Buy and hold strategy is used as a conservative approach and also as a passive investment strategy. It comprises of a procedure providing assistance to investors to buy or hold stock at a certain level of risk.

Toms (2012) explained moving average application as the practice of systematically buying and selling whenever the price crosses its average. Price moves in trends, this can be uptrend or it can be downtrend. The uptrend is defined as the rising of price, whereas the downtrend is declining. When the price cuts up its average from below the price is an upward trend and a buy signal is generated. Similarly, when the price cuts the average from above, it's called a downward trend and a sell signal is generated.

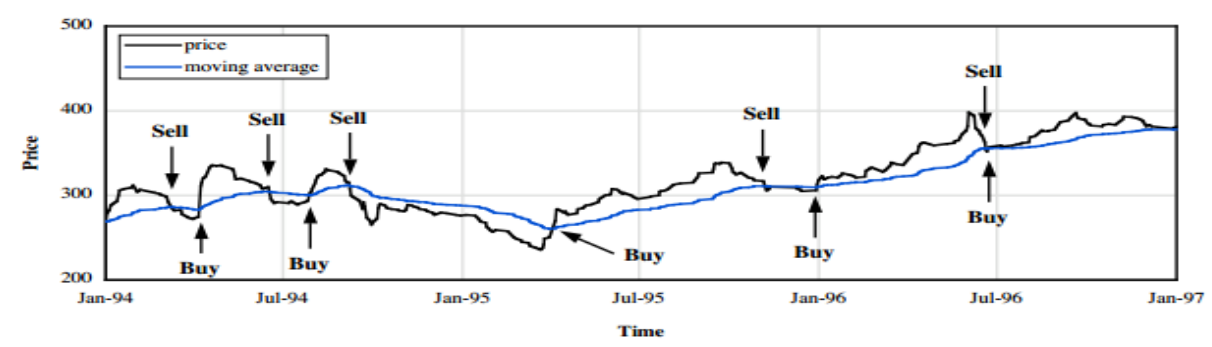

Figure 1. Example of moving average trading process 


\section{Materials and Methods}

This research is quantitative in nature and all analysis and calculations are carried forward with descriptive analysis. Quantitative as layman terms can be explained as research is the term for the particular systematic empirical exploration associated with social phenomena by using record, numerical or even numerical files or even computational strategies. The objective of quantitative research is usually to acquire and hire numerical versions, theories and/or ideas related to phenomena. This study is carrying all analysis in mathematical terms to justify the goal of the study.

Data on five global stock indices such as Dutch AEX, Dow Jones, S\&P 500, FTSE 100, and NASDAQ have been considered for analysis. To get a full overview of the strategy several MSCI indices were also evaluated to have diversified global portfolios (Jain, Sharma, \& Srivastava, 2019). Using MSCI indices would allow constructing cross-regional comparisons across all markets. Data has been gathered from DataStream, although a couple of sets have also been taken from the CRSP. This study has relied on monthly closing prices of the securities. The monthly closing prices of particular security have been converted to the different average lag-lengths using natural log function for the purpose of generating buy or sell signals.

Table 1. Summary of the securities used

\begin{tabular}{llll}
\hline & & Timeframe & No. of Months \\
\hline Stock Indices & AEX & $12 / 1985-12 / 2018$ & 398 \\
& Dow Jones & $01 / 1985-12 / 2018$ & 409 \\
& S\&P 500 & $01 / 1980-12 / 2018$ & 469 \\
& FTSE100 & $02 / 1994-12 / 2018$ & 301 \\
& NASDAQ & $10 / 1985-04 / 2014$ & 400 \\
Global Equity & MSCI EAFE & $12 / 1969-12 / 2018$ & 590 \\
& MSCI WORLD & $12 / 1969-12 / 2018$ & 590 \\
& MSCI Europe & $12 / 1969-12 / 2018$ & 590 \\
& MSCI EM & $12 / 1987-012 / 2018$ & 374 \\
\hline Total & & & 4121 \\
\hline
\end{tabular}

Total 4,121 number of months are considered as an observation in this paper. Table 1 reports the details of individual assets accounted for observation in this paper. Log returns are used to simplify the calculations.

\subsection{Market Timing Model}

Historical simulation-based moving averages have been taken in a way to smooth out the value of a security and plot average asset prices over time. The timing model strategy suggests that buy a security once it starts to trade above the average of its closing price from specified days or months and sell the security when its price falls below the same average. Thus, the buy or sell signal has been generated according to the following rule:

$$
\text { Signal }_{t+1}=\left\{\begin{array}{l}
\text { Buy if } P_{t}>S M A_{t}(\mathrm{k}), \\
\text { Sell if } P_{t}>S M A_{t}(\mathrm{k}) .
\end{array}\right.
$$

It has been assumed that the probability of stock return varies due to the continuous fluctuation in stock prices. Therefore multiple iterations of stock returns have been generated using Monte Conte simulation to get relative historical returns in timing model. A $k$-month Simulated Moving Average (SMA) at month-end is represented as follows:

$$
\begin{aligned}
S M A_{n} & =p_{1} * \frac{1}{n} \sum_{t=k-n+1}^{k} P_{t}+p_{2} * \frac{1}{n} \sum_{t=k-n+1}^{k} P_{t}+\cdots, p_{m} * \frac{1}{n} \sum_{t=k-n+1}^{k} P_{t} \\
& =\lim \sum_{m \rightarrow \infty}^{j} j \cdot \frac{1}{n} \sum_{t=k-n+1}^{k} P_{t}
\end{aligned}
$$


Where $n$ is the moving average length, $k$ is the period being considered from the total number of periods, and $P_{t}$ is the price of the security at time t. $\operatorname{Pt}(\mathrm{p} 1, \mathrm{p} 2, \ldots . \mathrm{pm})$ is the price of security at different points of time t. The notations $\lim \sum_{m \rightarrow \infty}^{j} j$ describes the unlimited time frame for the security prices and $\sum_{t=k-n+1}^{k} P_{t}$ shows the total sum of single security price. Stock market volatility is the term for the amount of uncertainty or chance regarding the size of changes in a security's value (Faber, 2007), can be described as:

$$
\text { Volatility }=\sum_{t=1}^{N} A_{b s}\left(\text { Price }_{t}-\text { Price }_{t-1}\right)
$$

Annual buy and hold returns of stock have been calculated using Compound Annual Growth Rate (CAGR) formula, where $n$ means a number of the time period, $B S V$ stands for beginning stock value and $E S V$ stands for ending stock value.

$$
C A G R=\left[\frac{B S V^{\frac{1}{n}}}{E S V}\right]-1
$$

\subsection{Results and Discussions}

Figures 2 and 3 show the stability of the five different stock indices and different MSCI indices respectively on log-scale values. NASDAQ is the best performing index, even during the tech-bubble of 1999-2001. During the time period of 1987-2018, US market has flourished and tech-innovations led NASDAQ to an all-time high before it was crashed in 2000. The MSCI-EM index shows the highest stability out of the four MSCI indices (as shown in Figure 3). During the time period of 1987-2018, emerging markets like China, India, Russia, and Brazil have improved as compared to the past and China a second-biggest economy in the world is a major contributor of MSCI-EM index (Hopewell, 2015).

\subsubsection{Comparison of Annual Return Using Normal Buy and Hold Strategy vs. Timing Model}

Table 2 shows the comparison of the annual performance of trading strategies used in this paper. In addition to this, SMA has found to be the best possible strategy to increase the returns and execute the trading plans in a better way. Similarly, Table 3 shows the volatility of the buy and hold strategy in comparison with different SMA trading strategies. Kilgallen (2012) and Marmi, Pacati, Renò and Risso (2013) have described the importance of volatility of return and have an inverse relationship with the return.

Previous studies showed that volatility is one of the most important factors as far as annual returns are a concern. In the study of Faber (2007) and later studies including a study conducted by Marmi et al. (2013) in University of Sienna, they conducted a study on tactical asset allocation by using daily date to actually determine the effect of daily data as compared to the monthly data used by Faber (2007). Now as far as volatility is concern, Faber (2007) and Marmi et al. (2013) study showed that volatility has Inverse relationship with the return. Less the volatility more will be the return and similarly if the volatility is high then return will decrease in the end. One critical reason behind that is the uncertainty in that situation when volatility is high because Investors in that situation become cautious as far as trading is concern as they don't know what will be the trend in the market.

\subsubsection{Key Findings of Timing Model Strategies}

- AEX shows the high volatility of 0.214 using the buy and hold strategy as compared to timing model strategies.

- In case of DJI, volatility value using the normal buy and hold strategy is 0.150 and with the use of the timing model, it drops down to 0.113 .

- S\&P 500 holds 0.157 value of volatility using the normal buy and hold strategy and 0.111 value using 10M-SMA which indicates the highest possible annual returns $7.80 \%$ with the use of 10M-SMA.

- In the case of FTSE 100 with the normal buy and hold volatility value is 0.170 and the best possible strategy is 6M-SMA with volatility value of 0.137 .

- In the case of NASDAQ, the volatility value of normal buy and hold strategy is 0.218 and with the use of 10M-SMA strategy, the value is 0.161 that is lowest in timing model strategies.

- In the MSCI World, the volatility of buy and hold 0.150 is higher than the timing model strategies. The lowest volatility 0.107 is by using $12 \mathrm{M}$-SMA strategy.

- $\quad$ MSCI-EAFE is providing a high return of $8.80 \%$ with the use of 10M-SMA. Because the volatility value of 
10M-SMA is lowest as compared to buy and hold volatility value of 0.170 .

- In MSCI-EM where a lot of technical trading happens, is showing the best performance and low volatility with the use of 4M-SMA with the value of 0.158 .

- $\quad$ MSCI Europe is best performing one when used in 8M-SMA strategy as far as volatility is concerned the value is 0.130 in time model and as compared to the normal buy and hold the value is 0.180 .

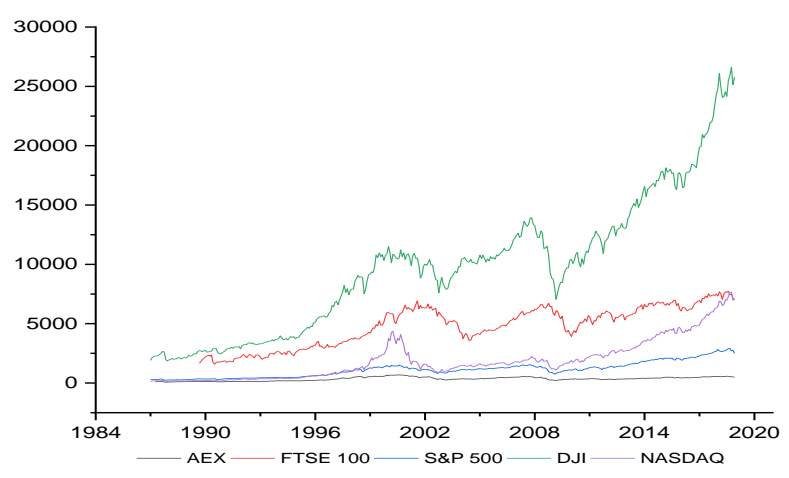

Figure 2. Time-series behavior of monthly asset prices of stock market indices 1987-2018

Table 2. Comparison of timing model annual returns with the use of normal buy and hold strategy

\begin{tabular}{|c|c|c|c|c|c|c|c|c|c|c|c|}
\hline \multirow[t]{3}{*}{ Indices } & $\begin{array}{c}\text { Buy and } \\
\text { hold }\end{array}$ & $\begin{array}{c}\text { Timing } \\
\text { model } \\
(10 \mathrm{M}-\mathrm{SMA})\end{array}$ & Difference & $\begin{array}{c}\text { Timing } \\
\text { model } \\
(4 \mathrm{M}-\mathrm{SMA})\end{array}$ & Difference & $\begin{array}{c}\text { Timing } \\
\text { model } \\
(6 \mathrm{M}-\mathrm{SMA})\end{array}$ & Difference & $\begin{array}{c}\text { Timing } \\
\text { model } \\
(8 \mathrm{M}-\mathrm{SMA})\end{array}$ & Difference & $\begin{array}{c}\text { Timing } \\
\text { model } \\
(12 \mathrm{M}-\mathrm{SMA})\end{array}$ & Difference \\
\hline & Annual & Annual & & Annual & & Annual & & Annual & & Annual & \\
\hline & Return & Return & & Return & & Return & & Return & & Return & \\
\hline AEX & $6.94 \%$ & $6.45 \%$ & $-0.49 \%$ & $7.05 \%$ & $0.11 \%$ & $7.02 \%$ & $0.08 \%$ & $6.75 \%$ & $-0.18 \%$ & $6.23 \%$ & $-0.71 \%$ \\
\hline DJI & $10.12 \%$ & $9.99 \%$ & $-0.12 \%$ & $10.29 \%$ & $0.17 \%$ & $10.24 \%$ & $0.12 \%$ & $10.09 \%$ & $-0.02 \%$ & $9.86 \%$ & $-0.26 \%$ \\
\hline S\&P 500 & $9.48 \%$ & $9.46 \%$ & $-0.02 \%$ & $9.89 \%$ & $0.41 \%$ & $9.82 \%$ & $0.34 \%$ & $9.65 \%$ & $0.17 \%$ & $9.24 \%$ & $-0.24 \%$ \\
\hline FTSE 100 & $3.82 \%$ & $4.32 \%$ & $0.49 \%$ & $4.26 \%$ & $0.44 \%$ & $4.49 \%$ & $0.66 \%$ & $4.49 \%$ & $0.67 \%$ & $4.22 \%$ & $0.40 \%$ \\
\hline NASDAQ & $16.16 \%$ & $15.19 \%$ & $-0.96 \%$ & $16.43 \%$ & $0.28 \%$ & $16.08 \%$ & $-0.07 \%$ & $15.52 \%$ & $-0.63 \%$ & $16.43 \%$ & $0.28 \%$ \\
\hline MSCI World & $7.50 \%$ & $7.52 \%$ & $0.02 \%$ & $7.64 \%$ & $0.14 \%$ & $7.63 \%$ & $0.13 \%$ & $7.60 \%$ & $0.10 \%$ & $7.43 \%$ & $-0.07 \%$ \\
\hline MSCI Europe & $7.58 \%$ & $7.47 \%$ & $-0.11 \%$ & $7.73 \%$ & $0.15 \%$ & $7.69 \%$ & $0.11 \%$ & $7.62 \%$ & $0.04 \%$ & $7.32 \%$ & $-0.26 \%$ \\
\hline MSCI-EM & $11.99 \%$ & $9.26 \%$ & $-2.74 \%$ & $11.50 \%$ & $-0.49 \%$ & $10.47 \%$ & $-1.52 \%$ & $9.71 \%$ & $-2.28 \%$ & $8.91 \%$ & $-3.08 \%$ \\
\hline MSCI-EAFE & $7.97 \%$ & $7.84 \%$ & $-0.13 \%$ & $8.08 \%$ & $0.11 \%$ & $8.04 \%$ & $0.07 \%$ & $7.94 \%$ & $-0.03 \%$ & $7.75 \%$ & $-0.22 \%$ \\
\hline Average & $9.06 \%$ & $8.61 \%$ & $-0.45 \%$ & $9.21 \%$ & $0.15 \%$ & $9.05 \%$ & $-0.01 \%$ & $8.82 \%$ & $-0.24 \%$ & $8.60 \%$ & $-0.46 \%$ \\
\hline
\end{tabular}

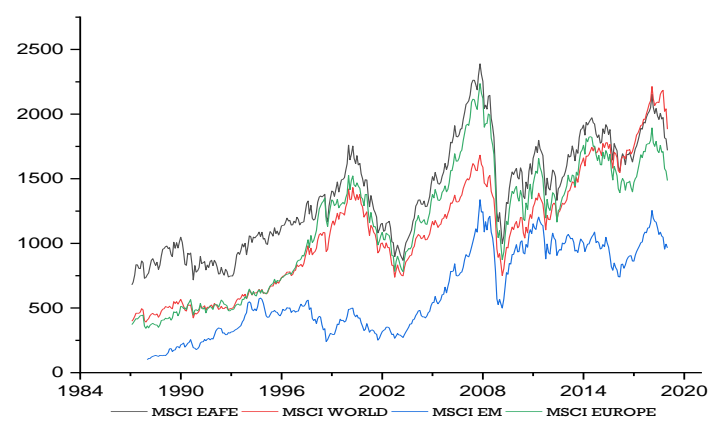

Figure 3. Performance of the different global MSCI indices 1987-2018 
Table 3. The volatility of the timing model using different SMA strategies

\begin{tabular}{|c|c|c|c|c|c|c|c|c|c|c|c|}
\hline Indices & $\begin{array}{l}\text { Annual } \\
\text { SD buy } \\
\text { and hold }\end{array}$ & $\begin{array}{l}\text { Annual SD } \\
\text { 10M-Timing }\end{array}$ & Difference & $\begin{array}{l}\text { Annual SD } \\
\text { 4M-Timing }\end{array}$ & Difference & $\begin{array}{l}\text { Annual SD } \\
6 \mathrm{M} \text {-Timing }\end{array}$ & Difference & $\begin{array}{l}\text { Annual SD } \\
\text { 8M-Timing }\end{array}$ & Difference & $\begin{array}{l}\text { Annual SD } \\
\text { 12M-Timing }\end{array}$ & Difference \\
\hline AEX & 0.214 & 0.159 & -0.055 & 0.162 & -0.05 & 0.161 & -0.053 & 0.162 & -0.052 & 0.165 & -0.049 \\
\hline DJI & 0.15 & 0.113 & -0.037 & 0.111 & -0.039 & 0.11 & -0.04 & 0.113 & -0.037 & 0.111 & -0.039 \\
\hline S\&P 500 & 0.157 & 0.111 & -0.046 & 0.112 & -0.046 & 0.112 & -0.046 & 0.112 & -0.045 & 0.112 & -0.045 \\
\hline FTSE 100 & 0.17 & 0.141 & -0.029 & 0.137 & -0.033 & 0.137 & -0.033 & 0.14 & -0.03 & 0.142 & -0.027 \\
\hline NASDAQ & 0.218 & 0.161 & -0.057 & 0.161 & -0.057 & 0.163 & -0.056 & 0.164 & -0.055 & 0.226 & 0.008 \\
\hline MSCI World & 0.15 & 0.11 & -0.04 & 0.109 & -0.041 & 0.108 & -0.042 & 0.108 & -0.042 & 0.107 & -0.044 \\
\hline MSCI-EAFE & 0.17 & 0.12 & -0.05 & 0.13 & -0.04 & 0.127 & -0.043 & 0.125 & -0.046 & 0.133 & -0.037 \\
\hline MSCI-EM & 0.24 & 0.16 & -0.08 & 0.158 & -0.082 & 0.168 & -0.072 & 0.165 & -0.075 & 0.165 & -0.075 \\
\hline MSCI Europe & 0.18 & 0.13 & -0.05 & 0.123 & -0.057 & 0.122 & -0.058 & 0.12 & -0.06 & 0.124 & -0.056 \\
\hline Average & 0.18 & 0.13 & -0.05 & 0.13 & -0.05 & 0.13 & -0.05 & 0.13 & -0.05 & 0.14 & -0.04 \\
\hline
\end{tabular}

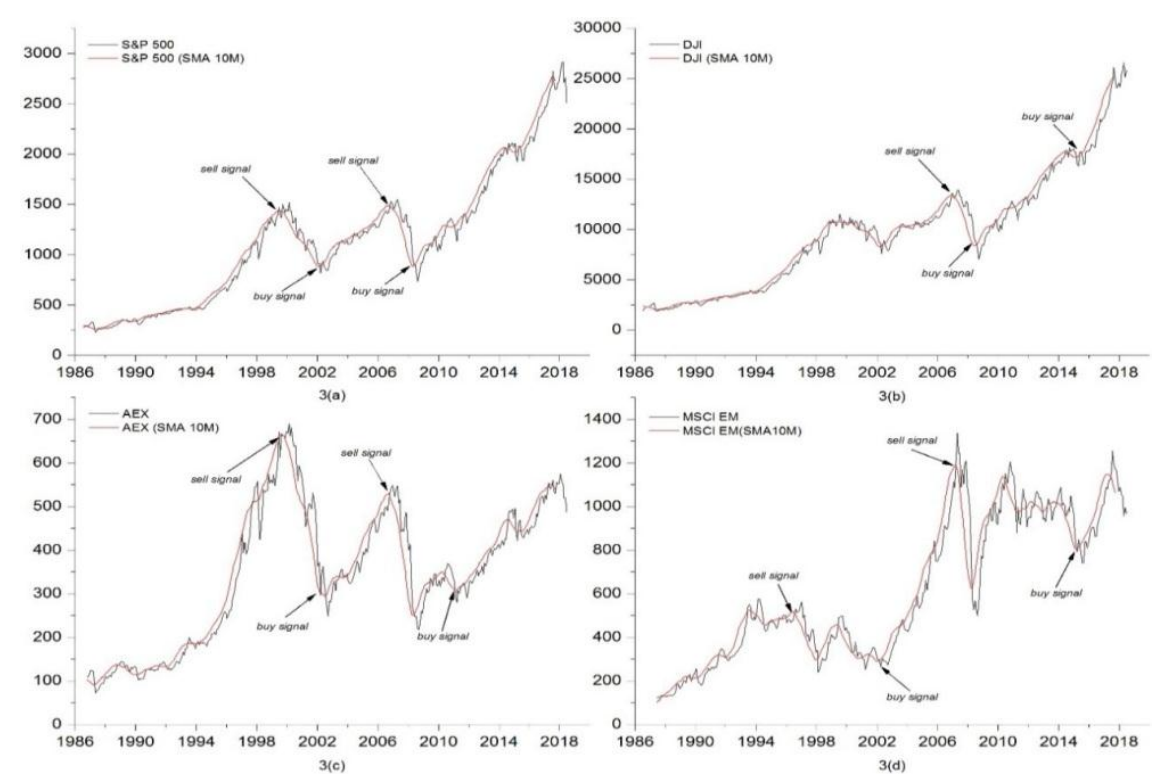

Figure 4. Best performing indices buy and hold signals 1987-2018

Table 4. Effectiveness of timing model strategies across global indices

\begin{tabular}{llllll}
\hline Indices & $\begin{array}{l}\text { Timing model } \\
\text { (Volatility) }\end{array}$ & $\begin{array}{l}\text { Timing model } \\
\text { (Lowest } \\
\text { Strategy) }\end{array}$ & $\begin{array}{l}\text { Timing model } \\
\text { (Lowest } \\
\text { Return) }\end{array}$ & $\begin{array}{l}\text { Timing } \\
\text { model (Highest } \\
\text { Strategy) }\end{array}$ & $\begin{array}{l}\text { Timing model } \\
\text { (Highest } \\
\text { Return) }\end{array}$ \\
\hline AEX & 0.159 & 10M-SMA & $6.86 \%$ & 10M-SMA & $6.86 \%$ \\
\hline DJI & 0.110 & 6M-SMA & $4.90 \%$ & $12 \mathrm{M}-$ SMA & $6.27 \%$ \\
\hline S\&P 500 & 0.111 & 10M-SMA & $7.80 \%$ & 12M-SMA & $7.95 \%$ \\
\hline FTSE 100 & 0.137 & 4M-SMA & $3.68 \%$ & 6M-SMA & $4.72 \%$ \\
\hline NASDAQ & 0.161 & 10M-SMA & $8.86 \%$ & 4M-SMA & $9.24 \%$ \\
\hline MSCI World & 0.107 & 12M-SMA & $7.52 \%$ & 10M-SMA & $7.95 \%$ \\
\hline MSCI-EAFE & 0.120 & 10M-SMA & $7.50 \%$ & 12M-SMA & $7.77 \%$ \\
\hline MSCI-EM & 0.158 & 4M-SMA & $10.89 \%$ & 4M-SMA & $10.89 \%$ \\
\hline MSCI Europe & 0.120 & 8M-SMA & $7.71 \%$ & 10M-SMA & $8.80 \%$ \\
\hline
\end{tabular}


Buy and sell signals describe market stock positioning. Figure 4 shows the buy and sell signals for important stocks that have been generated using 10M-SMA for better forecasting of returns. In a comparison of trading strategies, it is noted that timing model strategies have performed well in forecasting returns than traditional buy and hold strategies in all selected global indices. Table 4 shows the summary of key findings of timing model strategies across different aforementioned indices. The findings also suggest the effectiveness of timing model strategy in future decisions for particular stock index while considering historical return and validity.

\section{Conclusions}

The purpose of this paper is to measure the effectiveness of the timing model strategy as a profitable trading strategy in order to minimize the risk and increase the annual return of a portfolio. This study has utilized different timing model strategies in generating buy and sell signals and defining holding period in order to find out the best possible strategy to increase the annual return of a particular portfolio. Further, the study has investigated whether the risk-adjusted returns on equity among several asset classes can be improved by suggesting the right time to enter and exit out of the market using market timing model. This study helps the investors to select better forecasting strategy to enter and exit the market at the best of the time in order to maximize returns.

Results show that even in the worst possible conditions of a market crash like 1987 or financial crisis like 2007-2008, SMA strategy is the best possible approach to minimize the risk and increase annual return. Therefore, investors who are looking for investment in the global stock market need to use SMA strategy for market decisions in order to achieve a balanced portfolio.

This paper reveals that practical trading procedures have some predictive skills in these markets and returns of these strategies are more of the passive buy and hold strategy. It is also noted that outperformance is caused by the ability to predict the direction of the markets efficiently.

This study would help all tiers of finance to achieve the optimum results of their investment. Furthermore, this study will also help practitioners and researchers to understand and conduct further research on the investment strategies in stocks. Finally, there is an implication to trading practices: the basis for performance evaluation of stock market indices is on the risk-adjusted returns. In recent times, investments in emerging markets stocks have seen growth because of higher returns. The risk-adjusted perspective of investment in these markets should be accounted for market risk. Otherwise, level of performance will be evaluated incorrectly and compensation of dealers will be mutilated.

Future work could be done on the volatility modeling of worldwide stocks and indices by using multivariate copula-based volatility models because traditional volatility models are based on the assumptions that the returns are independent and normally distributed that lead to underestimation or overestimation of volatility.

List of Acronyms

\begin{tabular}{ll}
\hline Index/ Asset & Abbreviation \\
\hline AEX & Amsterdam Exchange index \\
DJI & Dow Jones Index \\
S\&P 500 & Standard \& Poor's 500 \\
FTSE 100 & Financial Times-Stock Exchange \\
NASDAQ & National Association of Securities Dealers Automated Quotations \\
MSCI-EAFE & The Morgan Stanley Country Index Europe, Australasia, Far East \\
MSCI World & Morgan Stanley Country Index World \\
MSCI Europe & Morgan Stanley Country Index Europe \\
MSCI-EM & Morgan Stanley Country Index Emerging Markets \\
SMA & Simulated Moving Average \\
CRSP & Centre for Research in Security Prices \\
\hline
\end{tabular}




\section{References}

Bessembinder, H., \& Chan, K. (1995). The profitability of technical trading rules in the Asian stock markets. Pacific-Basin Finance Journal, 3(2-3), 257-284. https://doi.org/10.1016/0927-538X(95)00002-3

Brock, W., Lakonishok, J., \& Lebaron, B. (1992). Simple Technical Trading Rules and the Stochastic Properties of Stock Returns. The Journal of Finance. https://doi.org/10.1111/j.1540-6261.1992.tb04681.x

Ciana, P. (2011). New Frontiers in Technical Analysis. New Frontiers in Technical Analysis: Effective Tools and Strategies for Trading and Investing. Hoboken, NJ, USA: John Wiley \& Sons, Inc. https://doi.org/10.1002/9781118531525

Dale, C., \& Workman, R. (1980). The Arc Sine law and tIle liii futures Market Tremsury. Financial Analysts Journal.

Droke, C. (2001). Moving Averages Simplified. United States of America: Marketplace Books. Retrieved from https://epdf.pub/queue/gann-simplified.html\#

Edwards, R. D., Magee, J., \& Bassetti, W. H. C. (2018). Technical Analysis of Stock Trends (11th ed.). New York: CRC Press. https://doi.org/10.4324/9781315115719

Faber, M. T. (2007). A Quantitative Approach to Tactical Asset Allocation. The Journal of Wealth Management, 9(4), 69-79. https://doi.org/10.3905/jwm.2007.674809

Fama, E. F. (2006). Efficient Capital Markets: A Review of Theory and Empirical Work. The Journal of Finance. https://doi.org/10.2307/2325486

Hopewell, K. (2015). Different paths to power: The rise of Brazil, India and China at the World Trade Organization. Review of International Political Economy, 22(2), 311-338. https://doi.org/10.1080/09692290.2014.927387

Jain, M., Sharma, G. D., \& Srivastava, M. (2019). Can Sustainable Investment Yield Better Financial Returns: A Comparative Study of ESG Indices and MSCI Indices. Risks, 7(1), 15. https://doi.org/10.3390/risks7010015

James, F. E. (1968). Monthly Moving Averages - An Effective Investment Tool?. Journal of Finance \& Quantitative Analysis. https://doi.org/10.1017/CBO9781107415324.004

Kilgallen, T. (2012). Testing the Simple Moving Average across Commodities, Global Stock Indices, and Currencies. The Journal of Wealth Management. https://doi.org/10.3905/jwm.2012.15.1.082

Marmi, S., Pacati, C., Renò, R., \& Risso, W. A. (2013). A quantitative approach to Faber's tactical asset allocation. International Journal of Computational Economics and Econometrics. https://doi.org/10.1504/ijcee.2013.056268

Murphy, J. J. (1999). Technical Analysis of the Financial Markets. New York Institute of Finance, Paramus, NJ. Retrieved from http://www.phdlrect.com

Toms, S. (2012). Accounting-based Risk Measurement: An Alternative to Capital Asset Pricing Model Derived Discount Factors. Australian Accounting Review. https://doi.org/10.1111/j.1835-2561.2012.00194.X

Turner, T. (2007). A beginner's guide to day trading online (2nd ed.). Adams Media. Retrieved from https://books.google.com.hk/books?hl=zh-CN\&lr=\&id=VkmHDgAAQBAJ\&oi=fnd\&pg=PR11\&ots=sUOCUG Kwxp\&sig=sUYIofz2zMk2AB367z1EeNzZdXA\&redir_esc=y\&hl=zh-CN\&sourceid=cndr\#v=onepage\&q\&f=f alse

Wong, W. K., Manzur, M., \& Chew, B. K. (2003). How rewarding is technical analysis? Evidence from Singapore stock market. Applied Financial Economics. https://doi.org/10.1080/0960310022000020906 